OPEN ACCESS

Edited by:

Meng Liang,

Tianjin Medical University, China

Reviewed by:

Cédric Emile Joseph Lenoir, Université Catholique de Louvain, Belgium

Benedict Alter,

University of Pittsburgh, United States

*Correspondence: Mathieu Piche mathieu.piche@uqtr.ca

Specialty section:

This article was submitted to Pain Research Methods,

a section of the journal

Frontiers in Pain Research

Received: 30 June 2021

Accepted: 11 October 2021

Published: 01 November 2021

Citation:

Provencher B, Northon S and Piché M (2021) Segmental Chiropractic Spinal Manipulation Does not Reduce Pain

Amplification and the Associated

Pain-Related Brain Activity in a Capsaicin-Heat Pain Model. Front. Pain Res. 2:733727. doi: 10.3389/fpain.2021.733727

\section{Segmental Chiropractic Spinal Manipulation Does not Reduce Pain Amplification and the Associated Pain-Related Brain Activity in a Capsaicin-Heat Pain Model}

\author{
Benjamin Provencher ${ }^{1,2}$, Stéphane Northon ${ }^{1,2}$ and Mathieu Piché ${ }^{1,2 *}$ \\ 1 Pain Neurophysiology Lab, Department of Anatomy, Université du Québec à Trois-Rivières, Trois-Rivières, QC, Canada, \\ ${ }^{2}$ CogNAC Research Group, Université du Québec à Trois-Rivières, Trois-Rivières, QC, Canada
}

Musculoskeletal injuries lead to sensitization of nociceptors and primary hyperalgesia (hypersensitivity to painful stimuli). This occurs with back injuries, which are associated with acute pain and increased pain sensitivity at the site of injury. In some cases, back pain persists and leads to central sensitization and chronic pain. Thus, reducing primary hyperalgesia to prevent central sensitization may limit the transition from acute to chronic back pain. It has been shown that spinal manipulation (SM) reduces experimental and clinical pain, but the effect of SM on primary hyperalgesia and hypersensitivity to painful stimuli remains unclear. The goal of the present study was to investigate the effect of SM on pain hypersensitivity using a capsaicin-heat pain model. Laser stimulation was used to evoke heat pain and the associated brain activity, which were measured to assess their modulation by SM. Eighty healthy participants were recruited and randomly assigned to one of the four experimental groups: inert cream and no intervention; capsaicin cream and no intervention; capsaicin cream and SM at T7; capsaicin cream and placebo. Inert or capsaicin cream (1\%) was applied to the T9 area. SM or placebo were performed 25 min after cream application. A series of laser stimuli were delivered on the area of cream application (1) before cream application, (2) after cream application but before SM or placebo, and (3) after SM or placebo. Capsaicin cream induced a significant increase in laser pain $(p<0.001)$ and laser-evoked potential amplitude $(p<0.001)$. However, SM did not decrease the amplification of laser pain or laser-evoked potentials by capsaicin. These results indicate that segmental SM does not reduce pain hypersensitivity and the associated pain-related brain activity in a capsaicin-heat pain model.

Keywords: SMT, pain modulation, spine, pain, manual therapy

\section{INTRODUCTION}

Musculoskeletal injuries generally lead to an inflammatory response, peripheral sensitization and primary hyperalgesia (1). This occurs with low back injuries, which are associated with acute pain and increased pain sensitivity at the site of injury, and in some cases, this leads to chronic primary low back pain (2-4). 
Primary hyperalgesia mostly results from peripheral mechanisms and is caused by nociceptor sensitization (5). The release of pro-inflammatory mediators, including serotonin, bradykinin, prostaglandins, arachidonic acid and substance $\mathrm{P}$ was shown to cause nociceptor sensitization in the injured tissues $(5,6)$. Thus, primary hyperalgesia is limited to the site of injury and is characterized by a decrease in pain threshold, an increased response to suprathreshold stimuli and spontaneous pain in the absence of external stimulation (5-7). When primary hyperalgesia affects the hairy skin, both $\mathrm{A} \delta$ and $\mathrm{C}$ nociceptors are sensitized to heat stimuli $(5,6,8)$. If primary hyperalgesia persists, sustained nociceptive inputs from C-nociceptors to spinal cord neurons lead to central sensitization, which can be evidenced by the presence of secondary hyperalgesia $(6,9,10)$. Secondary hyperalgesia is usually described as an increased sensitivity to mechanical, but not heat stimuli, in uninjured tissues outside the area of tissue injury $(6,7,11)$. Recent studies have shown that this relies on a class of A-nociceptors that project to sensitized spinal neurons in laminae I and $\operatorname{IV/V}(10,12,13)$. Central sensitization is common in chronic pain conditions (14). Features of central sensitization such as increased temporal summation and decreased pressure pain threshold in remote body parts (secondary hyperalgesia) are also frequently observed in chronic low back pain (15). Thus, reducing the intensity or the duration of primary hyperalgesia to prevent central sensitization and secondary hyperalgesia may limit the transition from acute to chronic pain.

Spinal manipulation (SM) is a form of manual therapy provided by different healthcare professionals, including chiropractors (16). SM has been shown to reduce both experimental and clinical pain $(17,18)$ and recent clinical practice guidelines recommend the use of SM for the management of back pain (19-22). Although several studies suggest that SM may decrease pain via segmental mechanisms involving the processing of C-nociceptor inputs in the spinal cord (23-26), these mechanisms are not fully understood, and the effect of SM on primary hyperalgesia remains unclear.

Two systematic reviews reported that SM decreases experimental pain in healthy volunteers $(17,18)$. Accordingly, several experimental studies demonstrated that SM could decrease experimental cutaneous pain in healthy volunteers $(23,24,27-30)$ and in patients with low back pain $(25,26)$, when the nociceptive activity is amplified by centrally mediated mechanisms like temporal summation and central sensitization. In addition, a recent meta-analysis reported that physical therapy (including manual therapy such as SM) improves nociceptive processing influenced by or related to central sensitization in patients with chronic musculoskeletal pain (31). Although it has never been demonstrated using neurophysiological measures, these findings suggest that SM affects the transmission of nociceptive activity or decreases nociceptive transmission in the dorsal horns of the spinal cord, regardless of the origin of the inputs (cutaneous or myofascial). Besides, a few studies suggest that the hypoalgesic effects of SM are partly due to decreased rigidity of the spine $(32,33)$. In these studies, however, SM were not performed specifically at one segment. Moreover, a recent study suggests that spinal stiffness is not the most important factor to produce SM-induced hypoalgesia (34). Furthermore, no clinically relevant association was observed between spine stiffness and mechanical pain thresholds (35), where increased stiffness was not associated with increased mechanical pain sensitivity, but rather with increased pain thresholds (lower pain sensitivity). Thus, although mechanical effects cannot be excluded, the hypoalgesic effects of SM may be independent of the improvement in mechanical function and may be produced when applied to joints without restriction, therefore supporting the observed effects in healthy volunteers.

Capsaicin pain models are widely used in pain research for the selective activation of nociceptors (36-38). Capsaicin is a chemical that is naturally present in chili peppers that binds to transient receptor potential vanilloid 1 (TRPV1), which is highly expressed in C-nociceptors (39). Low concentrations $(\leq 1 \%)$ of capsaicin applied topically initially excite C-nociceptors, resulting in a transient inflammatory response, pain, as well as primary and secondary hyperalgesia $(6,7,11,39)$. To our knowledge, two studies investigated the hypoalgesic mechanisms of SM on capsaicin pain, one reporting that a single SM session reduced capsaicin pain and the other showing no effect (30, 40). In addition to these conflicting findings that remain to be clarified, the underlying neurophysiological mechanisms of SM on heat pain amplification by capsaicin remain unknown.

The aim of the present study was to investigate the effects of SM on pain amplification using a capsaicin-heat pain model, in which laser pulses are applied on capsaicin-treated skin. We hypothesized that segmental SM would reduce the capsaicininduced amplification of laser heat pain, by reducing the associated increase in spinal nociceptive transmission. We also hypothesized that this reduction would result in reduced laserevoked potentials amplitude, partly reflecting the segmental inhibition of spinal nociceptive activity.

\section{MATERIALS AND METHODS}

\section{Participants}

Ninety participants were recruited by advertisement on the campus of Université du Québec à Trois-Rivières and on social media. Participants were included if they were between 18 and 55 years old. They were excluded if they reported acute or chronic pain, acute or chronic illness, psychiatric disorders, if they underwent spinal surgery, had a significant injury to the spine in the 3 months preceding the experiment, or took any medication or recreational drug during the 2 weeks prior to experimentation. They were also excluded if they presented a skin of type I on the Fitzpatrick scale, reported having an allergy/intolerance to chili peppers, or if their pain threshold exceeded the safety limit for laser stimulation (see section Painful Laser Stimulation). Eighty healthy volunteers [ 40 women and 40 men; aged $27.1 \pm 6.8$ years (mean $\pm S D)]$ were included and completed the study. A flow diagram of participants inclusion is presented in Figure 1. All experimental procedures conformed to the standards set by the latest revision of the Declaration of Helsinki and were approved by the Research Ethics Board of Université du Québec à Trois-Rivières. All participants gave written informed consent, acknowledging their right to withdraw from the experiment 


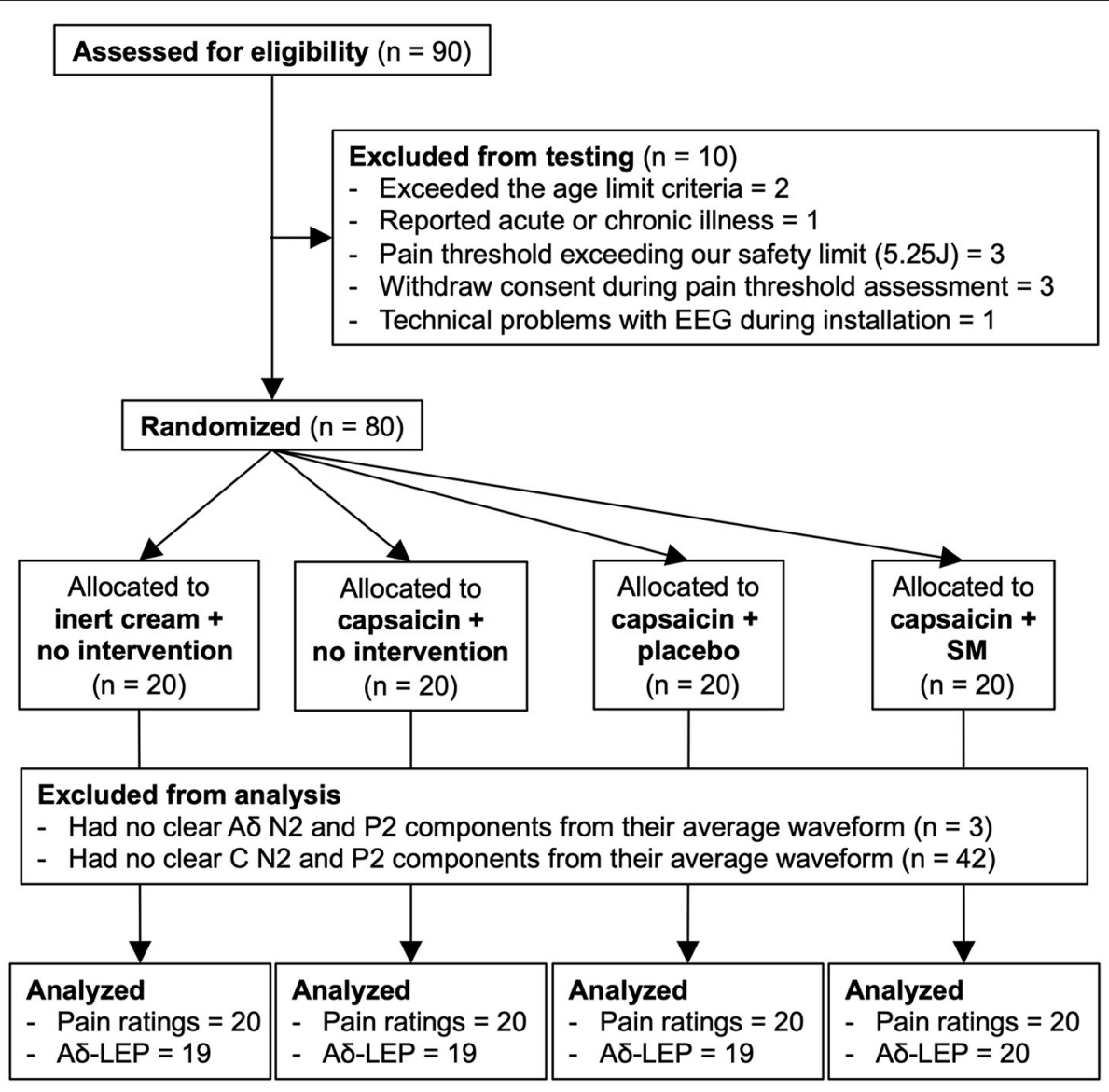

FIGURE 1 | Flow diagram of enrollment, allocation, and analyses. SM, spinal manipulation; LEP, laser-evoked potential.

without prejudice, and received a compensation of $\$ 25$ for their travel expenses, time and commitment.

\section{Experimental Design and Protocol}

This study relied on a mixed design to compare changes in laserevoked pain and brain activity between groups. Participants were randomly assigned to one of the four experimental groups using a random-number generator: inert cream with no intervention $(n=20)$; capsaicin cream and no intervention $(n=20)$; capsaicin cream and SM at T7 $(n=20)$; capsaicin cream and placebo intervention $(n=20)$.

During the experiment, room temperature was kept constant at $24^{\circ} \mathrm{C}$. All participants were seated on a regular desk chair with a low backrest (under T9 vertebra) during the first $25 \mathrm{~min}$ of the experiment, after which they were instructed to lay prone comfortably on a chiropractic table for the remaining $10 \mathrm{~min}$. This allowed the intervention to be delivered. Their head was slightly elevated by a thick towel placed under their chin to avoid pressure on the electrooculography (EOG) and frontal electroencephalography (EEG) electrodes. The participant and experimenter wore safety glasses designed for a $1,340 \mathrm{~nm}$ wavelength laser at all time. In both positions, participants were instructed to keep their eyes open, look at a fixation cross to minimize eye movement, and refrain movement as much as possible during stimulation.

The experimental protocol is illustrated in Figure 2. The experiment comprised three blocks of 30 laser stimuli delivered to the T9 area. After the first block, inert or capsaicin cream (1\%) was applied to the stimulation area and participants waited 20 min before the next block of laser stimuli. After this second block (25 min after cream application), either no intervention, SM or the placebo intervention (sham SM) were performed. For the groups with no intervention, participants simply waited for $60 \mathrm{~s}$ before the third block of laser stimuli was delivered. After each stimulation block, participants provided their pain ratings, and they could blink and stretch as needed. The timing of the intervention (25 min after cream application) was based on previous findings, which characterized the time course of tonic pain produced by capsaicin applied to the back (30). After $20 \mathrm{~min}$, capsaicin pain remains relatively stable, which allows to compare laser pain with baseline and pain amplification by capsaicin. This is more clinically relevant to investigate the hypoalgesic mechanisms of SM, since ongoing tonic pain is closer to what patients report with acute back pain. The laser stimulus 
allows confirming the amplification of pain by capsaicin and the measure of laser evoked potentials and their amplification by capsaicin.

\section{Painful Laser Stimulation}

Painful stimuli were produced by laser heat pulses generated by an infrared neodymium-doped yttrium aluminum perovskite laser (Nd:YAP, DEKA 1,340, Electronical Engineering, Florence, Italy). These stimuli have been shown to activate heat sensitive $A \delta$ and $C$ fibers selectively, while avoiding the activation of $A \beta$ fibers $(41,42)$. The laser beam was transmitted through a $10 \mathrm{~m}$ optic fiber cable and was adjusted to $7 \mathrm{~mm}\left(\approx 38.5 \mathrm{~mm}^{2}\right.$ area $)$, with a pulse duration of $5 \mathrm{~ms}$. Based on our prior experience with this type of laser and safety recommendations for repeated laser stimuli (43), a maximum fluence limit was set to $14 \mathrm{~J} / \mathrm{cm}^{2}$ (5.25 J intensity limit for a $7 \mathrm{~mm}$ laser beam diameter). The laser device was triggered using a stimulus presentation software (Spike2; Cambridge Electronic Design Limited, Cambridge, UK). To avoid stimulation of the same area twice, 25 tiny ink marks were drawn on the skin with a regular Hi-Tecpoint $0.5 \mathrm{~mm}-$ Black Pilot pen to guide the experimenter for the area to be stimulated, in a $5 \times 5 \mathrm{~cm}$ grid centered around T9 spinous process (T9-T10 dermatome). The laser was moved to the next point of the grid after each stimulus. No adverse event related to laser stimulation was observed by the experimenter during the experiment or reported by participants after the experiment.

The individual pain threshold was determined using a staircase procedure. Before pain threshold assessment, participants were instructed to focus on the warm/burning sensation in their back and to report pain intensity verbally after each stimulus using a numerical rating scale ranging from 0 to 100, 0 indicating "no pain" and 100 "the worse pain imaginable." Stimuli were delivered at an initial intensity of $0.5 \mathrm{~J}$ and stimulus intensity increased sequentially by $0.5 \mathrm{~J}$ increments until pain was reported (rating of $1 / 100$ or higher), or until the $5.25 \mathrm{~J}$ safety limit was reached. If no pain was reported (rating of $0 / 100$ ) at the highest energy laser stimulus within our safety limits (5.25 J), the participant was excluded from the study. This was necessary for the purpose of the study, in which we examined pain inhibition and not only LEPs. Three participants were excluded for this reason. Otherwise, the energy was increased sequentially again until a pain rating of at least 30/100 was reported or until the $5.25 \mathrm{~J}$ limit was reached. Participants were then familiarized with the selected intensity using five consecutive stimuli with an interstimulus interval varying between 5 and $10 \mathrm{~s}$. If the intensity was deemed acceptable for the participant, the experiment was continued. If the participant judged that the stimulus intensity produced pain that could not be tolerated for the duration of the experiment, stimulus intensity was decreased by $0.5 \mathrm{~J}$ and the familiarization procedure resumed until an acceptable stimulus intensity was reached. Once approved by the participant, the stimulus intensity was kept constant throughout the experiment.

\section{Capsaicin and Inert Creams}

The $1 \%$ capsaicin cream used for this experiment was prepared by a pharmaceutical laboratory (Gentès \& Bolduc pharmacists, St-Hyacinthe, QC, Canada). This concentration was used to produce tonic pain and hyperalgesia in prior studies (40, 4446). The inert cream consisted of the same petroleum jellybased cream without the active ingredient. After the first laser stimulation block, $\approx 1 \mathrm{~g}$ of cream was applied uniformly to the stimulated area in a layer $<1 \mathrm{~mm}$ thick and covered with transparent food-grade plastic film secured in place by adhesive tape. This ensured that the cream could not be wiped or spread out. After the experiment, the plastic film was discarded, the remaining cream removed, and the participants back carefully washed with water and soap to eliminate any trace of the cream. The burning sensation induced by capsaicin vanished within 30-120 min after the cream removal.

Instructions given to the participants were scripted for standardization and to minimize the influence of expectations. Participants were told which cream would be applied to their back (inert or capsaicin). However, they were not aware that other participants may receive a different cream. Moreover, none of the participants had used capsaicin cream before. Therefore, they were not aware that it could affect laser-evoked pain. Prior to the experiment, the information given to each participant was as follows: "After the first series of laser stimuli, we will apply $1 \mathrm{~g}$ of inert cream in your back. This will not do anything" OR "After the first series of laser stimuli, we will apply $1 \mathrm{~g}$ of capsaicin cream in your back. You may feel nothing at all, or you may notice a warm or burning sensation. These sensations are completely normal. We are interested to know how you will react to this cream." Later, when it was time to rate the spontaneous pain induced by capsaicin, the experimenter asked the following question: 1- Do you feel something in your back right now? If the participant said yes: 2- Do you consider this painful? If the participant said yes: 3How painful is it from 0 to 100 ?

\section{Spinal Manipulation and Placebo Intervention}

SM were performed by only one licensed chiropractor and consisted of a preload force followed by a short-duration, highvelocity, low amplitude, posterior to anterior thrust applied with both hands. SM was applied over the transverse processes of T7 vertebra, just outside the area where cream was applied, to generate audible release (cavitation). The contact point at T7-T8 for SM was selected to avoid painful SM due to the application of this mechanical force on the acutely inflamed and sensitized T9 area. SM directly applied at T9 may produce excitatory activity that could counter hypoalgesic effects. Moreover, since a single thrust affects several adjacent segments (47), SM applied as close as possible to the painful area while being outside the region of hypersensitivity would produce the most favorable outcomes. This type of manipulation lasts $<200 \mathrm{~ms}$ and involves a force of $\sim 500 \mathrm{~N}(48-51)$. The placebo intervention consisted of a sham spinal manipulation performed with the participant in the same position, but the chiropractor contacted the medial border of both scapulae to apply a preload force by moving the scapulae laterally. A high-velocity, low amplitude thrust was then applied in the scapula-thoracic plane. This type of sham manipulation has been used in previous studies and reported successful in blinding most of the participants $(52,53)$. 


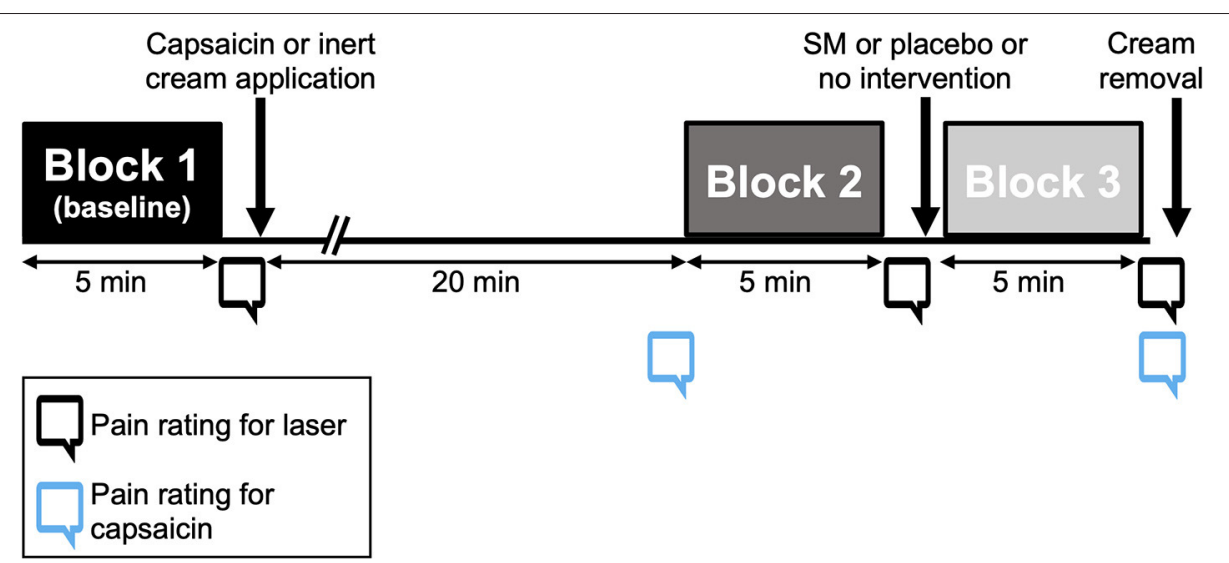

FIGURE 2 | Experimental protocol. Three blocks of 30 laser stimuli were applied to the back, for a total of 90 stimuli. After each block, participants were instructed to rate pain verbally. Inert or capsaicin cream was applied to the stimulation area after block 1 and removed at the end of the experiment. Between blocks 2 and 3 , participants received either no intervention, a placebo intervention or a spinal manipulation at T7.

No adverse event was reported by participants following SM or placebo.

\section{Pain Ratings}

After each series of 30 stimuli, participants were instructed to rate laser-induced pain verbally using a numerical rating scale ranging from 0 to 100,0 indicating "no pain" and 100 "worse pain imaginable." They were instructed to report the average pain induced by the 30 stimuli. Immediately before the second stimulation block (20 min after cream application), and immediately after the third stimulation block (30 min after cream application), participants with the capsaicin cream were also instructed to rate capsaicin-induced pain using the same pain rating scale.

\section{Expectations of Pain Modulation and Blinding}

To limit the effects of expectations, participants were not informed about the specific objective of the study or about the different groups receiving different interventions (SM or sham SM). They were informed that their back would be mechanically stimulated and that we were interested in measuring how this mechanical stimulus may influence pain-related brain activity. Expectations of pain modulation were measured using a visual analog scale (54). Before the second block of laser stimuli, participants were presented a form with the following question: "On the scale below, indicate the change in laser-pain intensity that you expect following the intervention in your back." The scale was a horizontal line ranging from -100 to 100 with the following anchors: $-100=$ "maximum decrease," $0=$ "no change" and $100=$ "maximum increase." Although participants were not aware that they belonged to different groups, we examined "blinding" by asking the following question to the two intervention groups: "Do you believe that the intervention you received was effective?"

\section{Electroencephalographic Recordings}

Electroencephalography (EEG) was recorded using a 64-channel BrainVision system with active $\mathrm{Ag}-\mathrm{AgCl}$ electrodes mounted on an actiCAP, according to the International 10-20 system (Brain Products, Gilching, Germany). Electrodes were nose-referenced, and the ground was set at FPz. Signals were sampled at $1,000 \mathrm{~Hz}$ and filtered using a $0.01-100 \mathrm{~Hz}$ band-pass filter. Eye movements and blinks were recorded using right eye EOG with electrodes placed at the suborbital ridge and just lateral to the external ocular canthus. Electrode impedance was kept below $20 \mathrm{k} \Omega$.

\section{Laser-Evoked Potentials Analyses}

EEG signals were analyzed offline using EEGLAB v2020.0 (55). After applying a $0.5-30 \mathrm{~Hz}$ finite impulse response band-pass filter (56-58), data were segmented into epochs extending from $-100 \mathrm{~ms}$ to $+1,500 \mathrm{~ms}$ relative to stimulus onset $(56,57,59,60)$. Epochs were baseline corrected using the -100 to $0 \mathrm{~ms}$ window $(56,58,60)$ and then visually inspected to reject epochs with artifacts (amplitude value exceeding $\pm 100 \mu \mathrm{V})(56-58,61)$. On average $3.2 \pm 2.4$ out of 90 epochs $(3.5 \%)$ were rejected. Data were then re-referenced to the common average and, an Infomax independent component analysis (ICA) was applied using the in-built EEGLAB function Runica to identify and remove components associated with noise (eye movements, eye blinks, cardiac and muscle artifacts) (55).

After data pre-processing, average waveforms were computed for each participant and stimulation block, and LEP components of interest were analyzed, including the $\mathrm{A} \delta$ and $\mathrm{C}$ fibers $\mathrm{N} 2$ and P2 (60-62). The A $\delta-\mathrm{N} 2$ was defined as the first major negative deflection occurring between 150 and $400 \mathrm{~ms}$ with a maximum amplitude at the vertex $(\mathrm{Cz})$, and the $\mathrm{A} \delta-\mathrm{P} 2$ was defined as the first major positive deflection occurring between 250 and $500 \mathrm{~ms}$ with a maximum amplitude at the vertex $(\mathrm{Cz})$. The $\mathrm{C}-\mathrm{N} 2$ was defined as the first major negative deflection following the A $\delta$-P2 and occurring between 350 and $1,500 \mathrm{~ms}$ with a maximum amplitude at the vertex $(\mathrm{Cz})$. The C-P2 was defined as the first major positive deflection 
TABLE 1 | Pain ratings for the four experimental groups (mean \pm SD).

\begin{tabular}{|c|c|c|c|c|c|}
\hline & & \multirow{2}{*}{$\frac{\text { Inert cream }}{\text { No intervention }}$} & \multicolumn{3}{|c|}{ Capsaicin cream } \\
\hline & & & No intervention & Placebo & SM \\
\hline \multirow[t]{3}{*}{ Laser pain } & Block 1 & $22.5 \pm 4.8$ & $21.8 \pm 12.3$ & $15.9 \pm 8.2$ & $24.5 \pm 14.3$ \\
\hline & Block 2 & $15.2 \pm 2.1$ & $47.3 \pm 6.5$ & $32.0 \pm 5.0$ & $45.3 \pm 8.3$ \\
\hline & Block 3 & $11.8 \pm 4.0$ & $51.1 \pm 7.9$ & $32.0 \pm 5.0$ & $48.0 \pm 7.6$ \\
\hline \multirow[t]{2}{*}{ Capsaicin pain } & Block 2 & & $25.4 \pm 8.9$ & $15.6 \pm 6.2$ & $21.1 \pm 7.4$ \\
\hline & Block 3 & & $29.8 \pm 8.9$ & $20.5 \pm 6.2$ & $26.9 \pm 7.4$ \\
\hline
\end{tabular}

following the C-N2 and occurring between 400 and 1,500 ms with a maximum amplitude at the vertex $(\mathrm{Cz})$. An independent assessment performed by two of the experimenters (BP and $\mathrm{MP})$ revealed that from the 80 participants tested, $3(\approx 4 \%)$ did not have clear $\mathrm{A} \delta-\mathrm{N} 2$ and $\mathrm{A} \delta$-P2 peaks from their average waveforms and a majority of participants did not have clear C$\mathrm{N} 2$ and C-P2 peaks. Thus, the N2 and P2 calculations were performed on data from the remaining 77 participants for $\mathrm{A} \delta$ fibers and C-LEP analyses are not presented. However, all data are shown in Supplementary Figure 1. For the LEP amplitude analysis, the N2-P2 peak-to-peak amplitude was preferred for quantification to limit inter-individual amplitude variability; in some participants, the N2 was of normal amplitude and latency, normal topographic distribution, but was shifted from baseline, leading to incorrect amplitude measurements. The peak-topeak analysis counter this issue although the potential effects on specific components cannot be examined. This was a fair compromise since modulation of LEPs in this study is presumed to occur due to spinal modulation of nociceptive transmission and thus to mostly reflect the resulting ascending information.

\section{Statistical Analysis}

Statistical analyses were conducted using Statistica v13.5 (Kivuto Solutions Inc., Ottawa, ON, Canada). All results are expressed as mean \pm SD. SD values were corrected to remove between-subject variability (63). Statistical threshold was set at $p<0.05$. Data distribution was assessed for normality with the KolmogorovSmirnov test and homogeneity of variance was assessed using Levene's test. To assess if the amplification of pain and nociceptive brain responses was induced by capsaicin, the data from block 2 relative to block 1 (difference) were compared between the four groups using one-way ANOVAs. To examine the effects of SM on capsaicin pain, and the amplification of pain and nociceptive brain responses, mixed ANOVAs were performed. These ANOVAs comprised 2 factors: groups (the 3 groups with capsaicin cream) and time (block 2 and 3). Bonferroni-corrected planned contrasts were used to decompose significant effects. Effect sizes are reported based on partial eta-squared $\left(\eta_{p}^{2}\right)$.

\section{RESULTS}

\section{Laser Stimulation Intensity and Capsaicin Pain}

The mean laser stimulation intensity for each group was $4.6 \pm$ $1.0 \mathrm{~J}$ for inert cream with no intervention, $4.9 \pm 0.5 \mathrm{~J}$ for capsaicin cream and no intervention, $4.6 \pm 1.0 \mathrm{~J}$ for capsaicin cream and $\mathrm{SM}$, and $4.8 \pm 0.7 \mathrm{~J}$ for capsaicin cream and placebo intervention. A one-way ANOVA revealed no significant difference between groups $\left(\mathrm{F}_{3,76}=0.81, p=0.49 ; \eta_{p}^{2}=0.03\right)$.

Capsaicin pain ratings are reported in Table $\mathbf{1}$ and presented in Figure 3. Capsaicin pain was not significantly different between groups (main effect: $\mathrm{F}_{2,50}=2.3, p=0.11, \eta_{p}^{2}=0.09$ ) or between groups over time (interaction: $\mathrm{F}_{2,50}=0.6, p=0.58$, $\left.\eta_{p}^{2}=0.02\right)$. This indicates that $\mathrm{SM}$ did not reduce capsaicin pain.

\section{Heat Pain Amplification Induced by Capsaicin}

Pain ratings for laser stimulation are reported in Table 1. Out of the 60 participants on which capsaicin cream was applied, 54 (90\%) reported increased sensitivity to laser stimuli during the second block. This number increased to 57 participants (95\%) during the third stimulation block. Thus, 3/60 participants (2 in SM and 1 in placebo intervention group) did not show heat pain amplification during the experiment.

To confirm that capsaicin induced heat pain amplification, changes in laser pain after the cream application but before any intervention were compared between groups using a one-way ANOVA (see Figure 4). The change in laser pain was significantly different between groups $\left(\mathrm{F}_{3,76}=16.7, p<0.0001, \eta_{p}^{2}=0.40\right)$. Bonferroni-corrected planned contrasts revealed that the change in laser pain was greater in the three groups with capsaicin cream compared with the group with inert cream (all $p<0.001)$.

\section{Effects of SM on Heat Pain Amplification}

To examine the effects of interventions on heat pain amplification, changes in laser-pain relative to baseline were compared between the three groups with capsaicin cream (see Figure 5). Changes in laser-pain intensity significantly increased between blocks 2 and 3 (main effect: $\mathrm{F}_{1,57}=6.17, p=0.02, \eta_{p}^{2}=$ $0.10)$. However, this effect was not significantly different between groups (interaction: $\mathrm{F}_{2,57}=1.69, p=0.19, \eta_{p}^{2}=0.06$ ), indicating that heat pain amplification was not reduced by SM.

\section{Amplification of A $\delta$ Laser-Evoked Potentials by Capsaicin}

Average waveforms and topographic maps for A $\delta$ N2 and P2 components for all groups and conditions are presented in Figure 6. As expected, both components showed a central scalp distribution and were maximal at the vertex. 


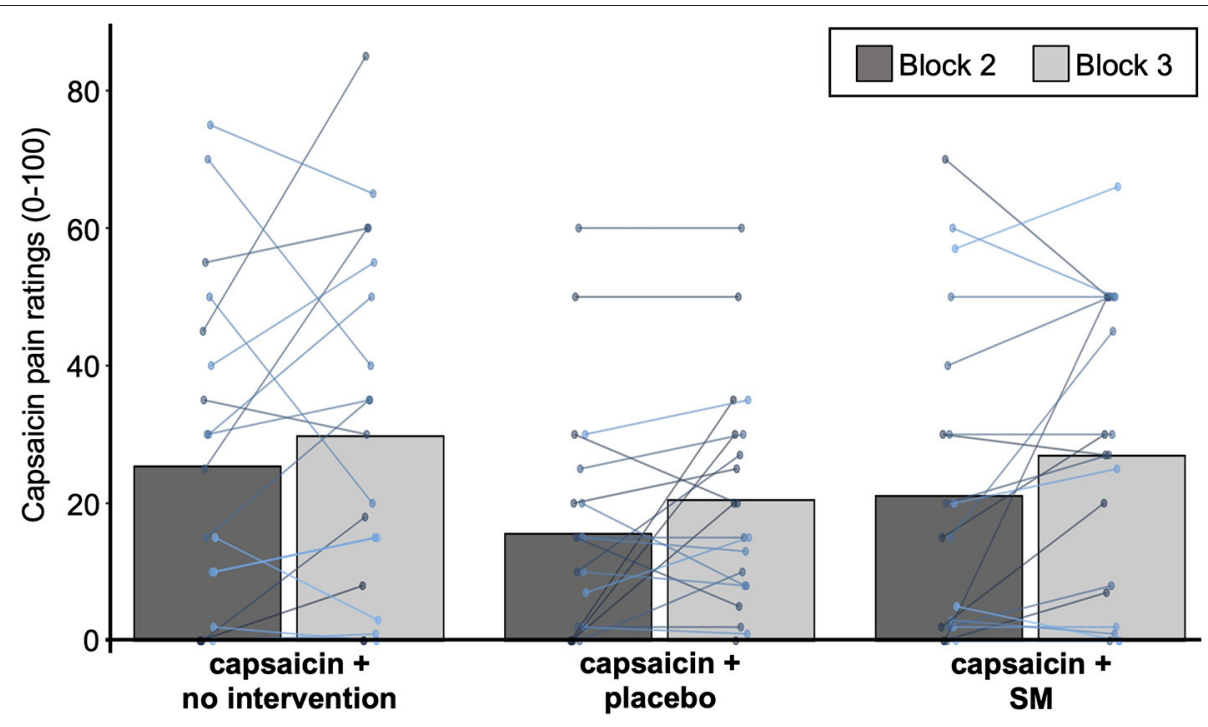

FIGURE 3 | Capsaicin pain ratings. Mean pain ratings for capsaicin pain for the three groups with capsaicin cream. Data from each participant are represented by linked colored points and the mean of these data points for each block is represented by gray bars.

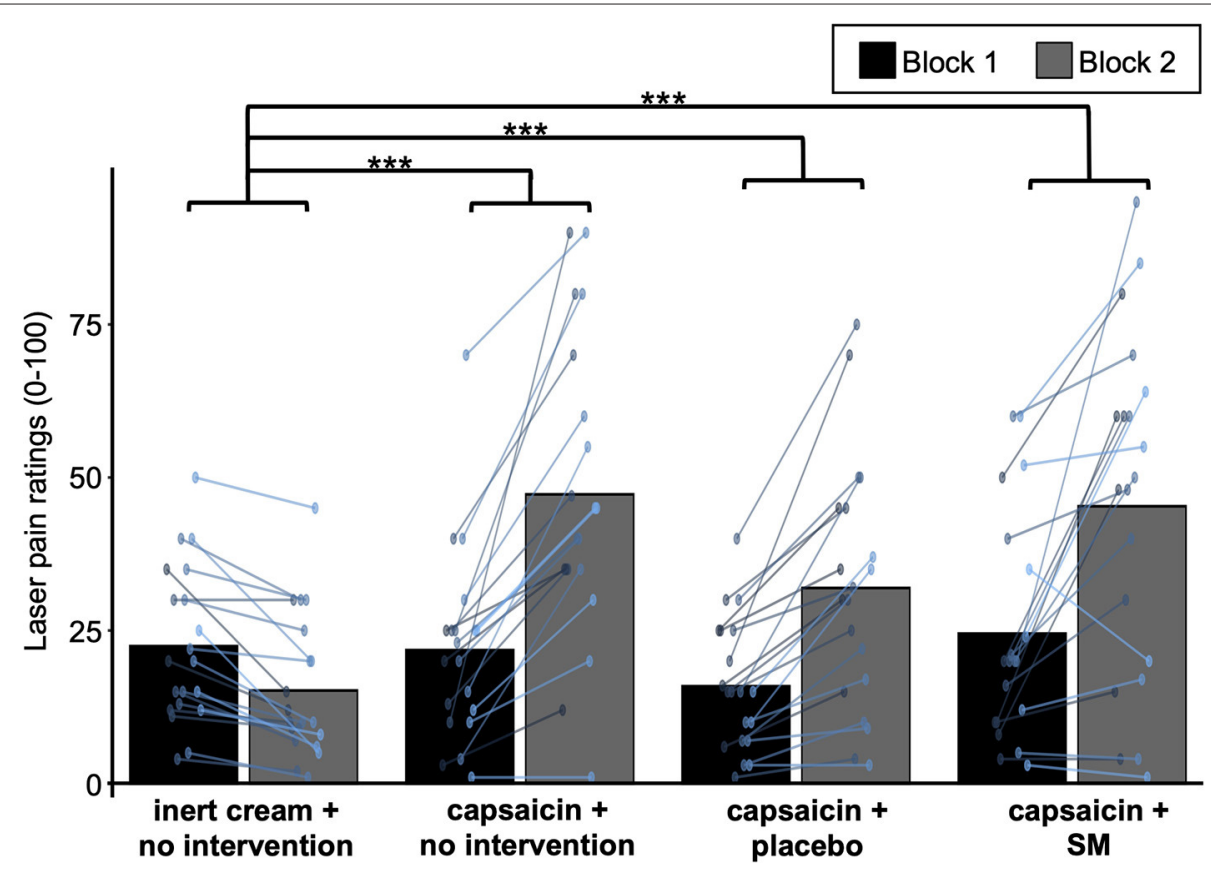

FIGURE 4 | Heat pain amplification induced by capsaicin. Mean laser pain ratings during block 1 and block 2 (before and after cream application, but before the intervention) for the four experimental groups. Data from each participant are represented by colored points and the mean of these data points for each block is represented by gray bars. ${ }^{\star \star \star} P<0.001$.

A $\delta$ N2-P2 amplitudes and latencies are reported in Tables 2, 3. The effect of capsaicin on A $\delta$ N2-P2 amplitude is presented in Figure 7. For the change from block 1 to block 2, A $\delta$ N2P2 amplitude was significantly different between groups (main effect: $\mathrm{F}_{3,73}=12.7, p<0.001, \eta_{p}^{2}=0.34$ ). Bonferroni-corrected planned contrasts revealed that compared with the inert cream group, A $\delta$ N2-P2 amplitude was significantly increased in the three groups with the capsaicin cream (all $p<0.001$ ). Moreover, A $\delta$ N2 peak latency was significantly different between groups from block 1 to block 2 (interaction: $\mathrm{F}_{3,73}=6.3, p<0.001, \eta_{p}^{2}$ $=0.21$ ). Bonferroni-corrected planned contrasts revealed that compared with the inert cream group, the $\mathrm{A} \delta \mathrm{N} 2$ peak latency was shorter for block 2 compared with block 1 in the capsaicin with no intervention group $(p<0.001)$, in the placebo intervention 


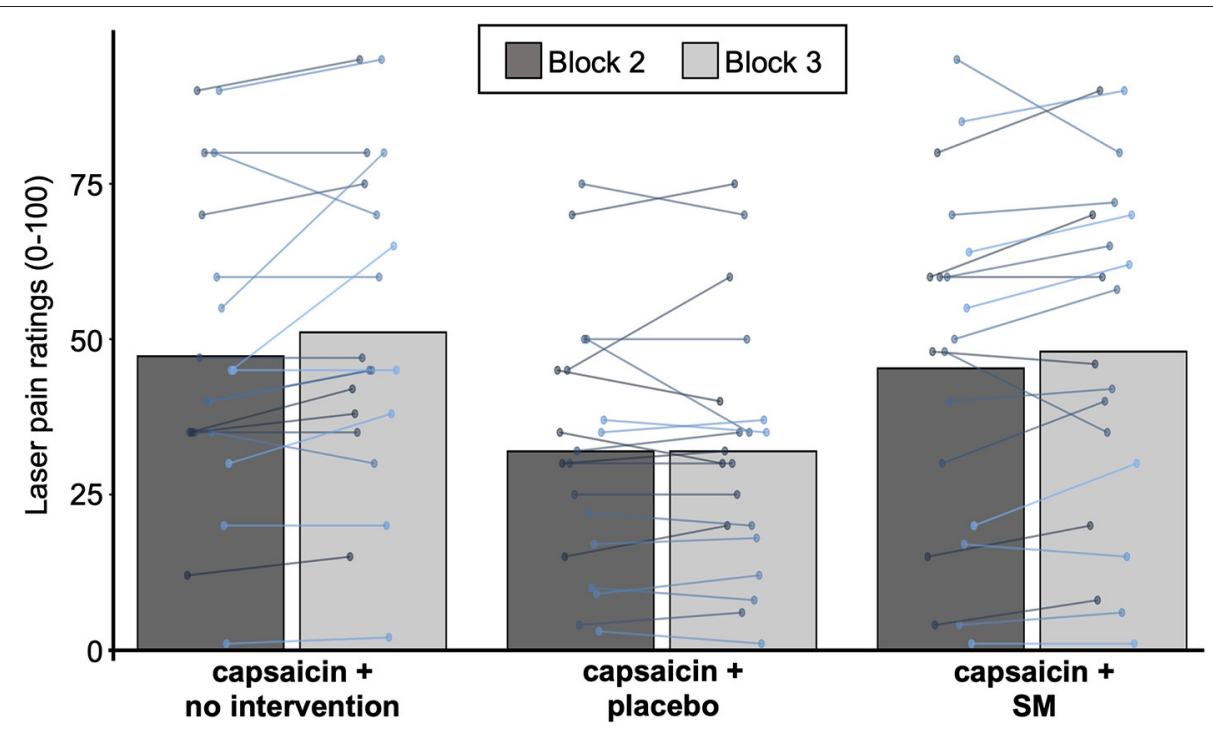

FIGURE 5 | Effect of SM on heat pain amplification. Mean laser pain ratings for the three groups with capsaicin cream during block 2 and block 3 (before and after the intervention). Data from each participant are represented by linked colored points and the mean of these data points for each block is represented by gray bars. Note that the inert cream group did not report heat pain amplification and received no intervention, so it is not included in this analysis.

groups $(p<0.001)$, but not in the SM group $(p=0.21)$. Similarly, A $\delta$ P2 peak latency was significantly different between groups from block 1 to block 2 (interaction: $\mathrm{F}_{3,73}=6.2, p<0.001, \eta_{p}^{2}$ $=0.20)$. Bonferroni-corrected planned contrasts revealed that the A $\delta$ P2 peak latency was shorter at block 2 in the capsaicin with no intervention group $(p=0.006)$, in the placebo intervention group $(p<0.001)$, but not in the SM group $(p=0.78)$ when compared with the inert cream group.

Altogether, these results indicate that heat pain amplification by capsaicin was associated with increased A $\delta$ N2-P2 amplitude and decreased $\mathrm{A} \delta \mathrm{N} 2$ and $\mathrm{P} 2$ peak latencies.

\section{Effects of SM on the Amplification of A $\delta$ Laser-Evoked Potentials by Capsaicin}

The effects of interventions on the amplification of $A \delta$-nociceptor activity by capsaicin were examined with the three capsaicin groups (see Figure 8). A $\delta$ N2-P2 amplitude was significantly different between groups over time (interaction: $F_{2,55}=3.3$, $\left.p=0.043, \eta_{p}^{2}=0.11\right)$. Bonferroni-corrected planned contrasts revealed that the change between block 2 and block 3 was significantly different between the SM and placebo intervention groups $(p=0.043)$, where the SM group did not show a decrease in A $\delta$ N2-P2 amplitude. However, no significant difference was observed between the SM and no intervention groups $(p=0.08)$.

Besides, A $\delta$ N2 peak latency was not significantly different between groups over time (from block 2 to block 3) (interaction: $\left.\mathrm{F}_{2,55}=0.05, p=0.95, \eta_{p}^{2}=0.002\right)$, but the effect was significant for the P2 latency (interaction: $\mathrm{F}_{2,55}=4.1, p=0.02, \eta_{p}^{2}=$ $0.13)$. However, Bonferroni-corrected planned contrasts revealed that P2 peak latency in block 3 was not significantly different between the SM group compared with the placebo group ( $p=$
0.06), although it was significantly different compared with no intervention group $(p=0.02)$.

\section{Expectations and Blinding}

Expectations scores were $1.2 \pm 32.4$ for the SM group and -5.7 \pm 16.6 for the placebo group. An independent $t$-test revealed no significant difference between groups $\left[t_{(38)}=0.83, p=0.41\right.$; $\left.\eta_{p}^{2}=0.02\right]$. In addition, expectations did not predict changes in capsaicin pain, laser pain or A $\delta$ N2-P2 amplitude, induced by SM (all $\mathrm{R}^{2}<0.08$, all $p>0.2$ ), or by the placebo (all $\mathrm{R}^{2}<0.17$, all $\left.p>0.07\right)$. Regarding blinding, the number of participants reporting that they received an effective intervention was not significantly different between groups [SM: 9/20 (45\%); placebo intervention: $\left.7 / 20(35 \%) ; \chi_{(1)}^{2}=0.36, p=0.55\right]$. Besides, expectations of pain relief were not significantly different between participants reporting that they received an effective vs. ineffective intervention for the SM group (Mann-Whitney $U=$ $42.5, p=0.62$ ), for the placebo group (Mann-Whitney $U=32.0$, $p=0.30$ ) or both groups combined (Mann-Whitney $U=182.0$, $p=0.79)$.

\section{DISCUSSION}

The aim of the present study was to investigate the effects of segmental chiropractic SM on heat pain amplification produced by capsaicin. The application of topical capsaicin in the back induced heat pain amplification and increased nociceptive brain activity associated with the activation of A- $\delta$ fibers. However, contrary to our hypothesis, SM did not reduce heat pain amplification and the associated amplification of nociceptive brain activity. 

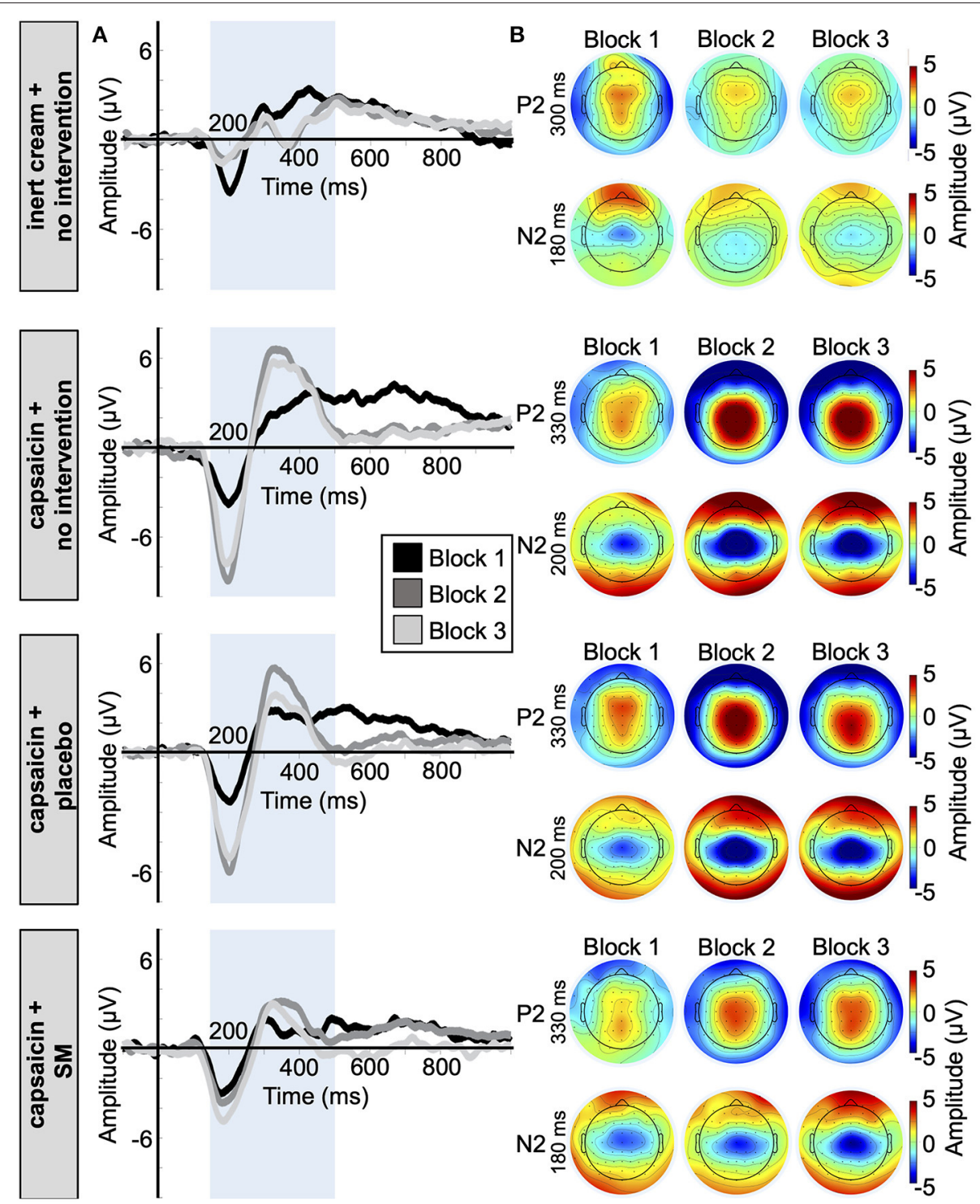

FIGURE 6 | A $\delta$ fiber laser-evoked potentials. (A) Average waveforms for the N2 and P2 at Cz with a nose reference of the 77 participants included in the A $\delta$ fiber LEP analysis, time-locked to the onset of laser stimulation. (B) Average topographic maps for the A $\delta$-N2 and A $\delta-P 2$ in the four groups.

TABLE 2 | A $\delta$ N2-P2 peak to peak amplitude ( $\mu$ V) for the four experimental groups (mean $\pm S D$ ).

\begin{tabular}{|c|c|c|c|c|c|}
\hline & & $\frac{\text { Inert cream }}{\text { No intervention }}$ & \multicolumn{3}{|c|}{ Capsaicin cream } \\
\hline & Block 2 & $6.9 \pm 1.7$ & $20.0 \pm 3.4$ & $16.3 \pm 3.4$ & $11.2 \pm 1.9$ \\
\hline & Block 3 & $5.8 \pm 2.2$ & $17.5 \pm 3.1$ & $13.4 \pm 3.3$ & $11.5 \pm 3.6$ \\
\hline
\end{tabular}

\section{Heat Pain Amplification Induced by Capsaicin}

The tonic pain and heat pain amplification induced by topical capsaicin reported in the present study are consistent with the effects reported previously $(37,39,64)$. Moreover, the increase in A $\delta$ LEP amplitude is consistent with the effects of nociceptive laser stimuli on capsaicin treated skin $(44,65-67)$. By contrast, a decrease in A $\delta$ LEP amplitude on capsaicin treated skin was reported in one study (68). However, this discrepancy is likely due to the lower concentration of capsaicin [ $0.1 \%$ instead of $0.6 \%$ 
TABLE 3 | N2 and P2 peak latency (ms) for the four experimental groups (mean \pm SD).

\begin{tabular}{|c|c|c|c|c|c|c|}
\hline & & & $\frac{\text { Inert cream }}{\text { No intervention }}$ & \multicolumn{3}{|c|}{ Capsaicin cream } \\
\hline & & Block 2 & $274.5 \pm 31.3$ & $204.4 \pm 22.2$ & $204.7 \pm 27.9$ & $212.1 \pm 20.3$ \\
\hline & & Block 3 & $272.1 \pm 46.5$ & $203.3 \pm 29.0$ & $205.2 \pm 26.8$ & $211.5 \pm 23.9$ \\
\hline & P2 & Block 1 & $405.4 \pm 39.1$ & $408.9 \pm 52.2$ & $421.6 \pm 55.6$ & $382.3 \pm 51.2$ \\
\hline & & Block 3 & $380.8 \pm 51.0$ & $354.5 \pm 26.2$ & $352.7 \pm 30.0$ & $352.4 \pm 40.5$ \\
\hline
\end{tabular}

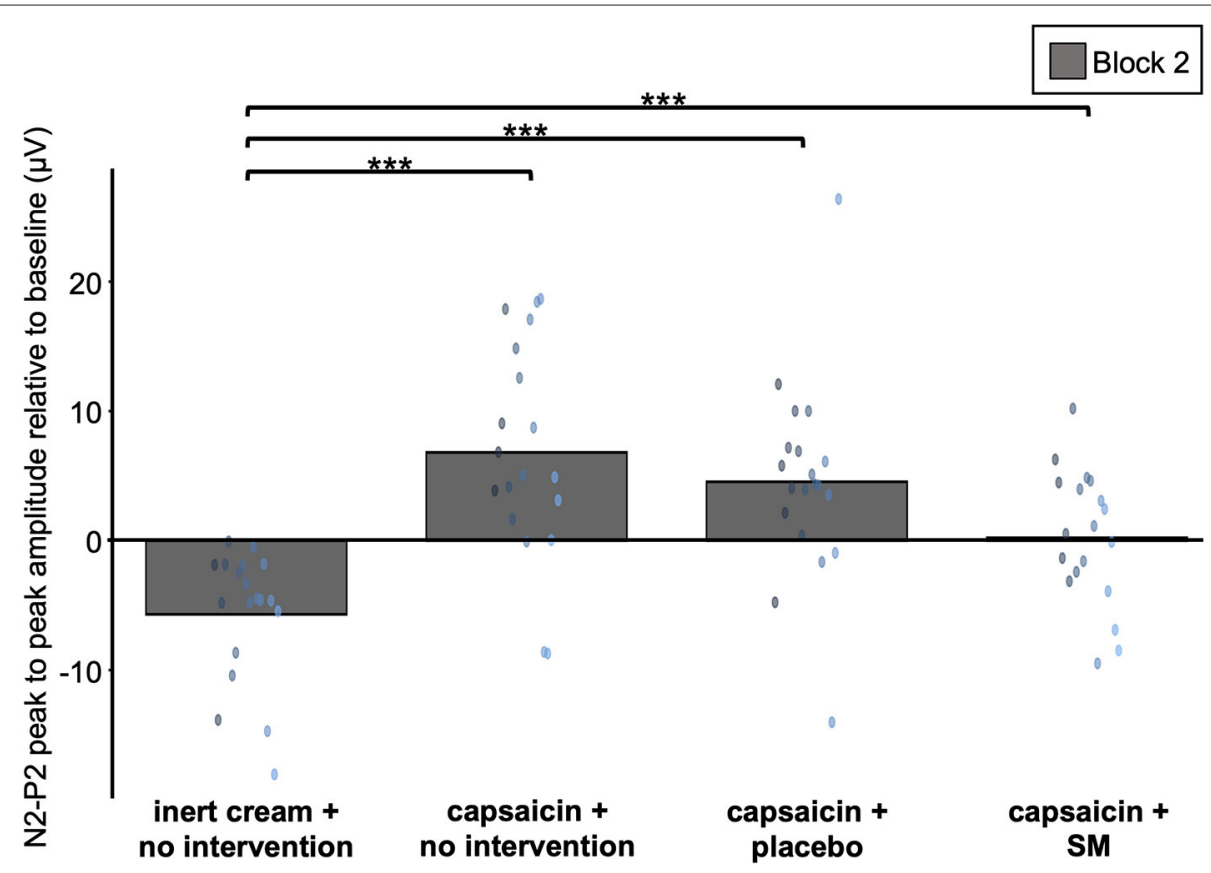

FIGURE 7 | Amplification of A $\delta$ fiber LEP by capsaicin. Average A $\delta$ fiber N2-P2 peak to peak amplitude values during block 2 for the four experimental groups. These values are relative to baseline (block 2 minus block 1). Data from each participant are represented by colored points and the mean of these data points for each block is represented by gray bars. ${ }^{\star \star \star} P<0.001$.

(66) or $1 \%$ in the present study and in $(44,65,67)]$. It should be noted that the amplitude of A- $\delta$ LEPs in the SM group of the present study was less affected by capsaicin and this may have affected the results. However, capsaicin-evoked pain, laserevoked pain, laser stimulation intensity, and expectation scores were not significantly different between groups. Therefore, these factors are unlikely to explain the smaller effect of capsaicin on A- $\delta$ LEPs in the SM group, which may reflect variability.

\section{Effects of Spinal Manipulation on the Amplification of Heat Pain and Nociceptive Brain Activity by Capsaicin}

In the present study, the capsaicin-heat pain model was used for its ability mimic some aspects of pathological pain such as spontaneous pain and increased pain sensitivity (38), which are commonly associated with low back pain $(69,70)$. Indeed, topical capsaicin has been used in previous studies to induce experimental low back pain (71) and neck pain (72).

The present findings show that SM has no effect on this type of experimental back pain or on the increased sensitivity to painful laser stimuli in the present experimental conditions. This is consistent with results from a recent study in which segmental SM reduced secondary mechanical hyperalgesia induced by capsaicin but not capsaicin pain (30). However, this contrasts with results from a previous study in which capsaicin pain was reduced by SM (40). Nonetheless, several factors may explain these discrepancies.

Firstly, the application of a mechanical force such as SM on an acutely inflamed and sensitized area activates nociceptive afferents, which excitatory activity may counter centrallymediated hypoalgesic effects. Accordingly, in the study that reported a reduction in capsaicin pain, topical capsaicin was applied to the forearm and SMs were not performed on sensitized 


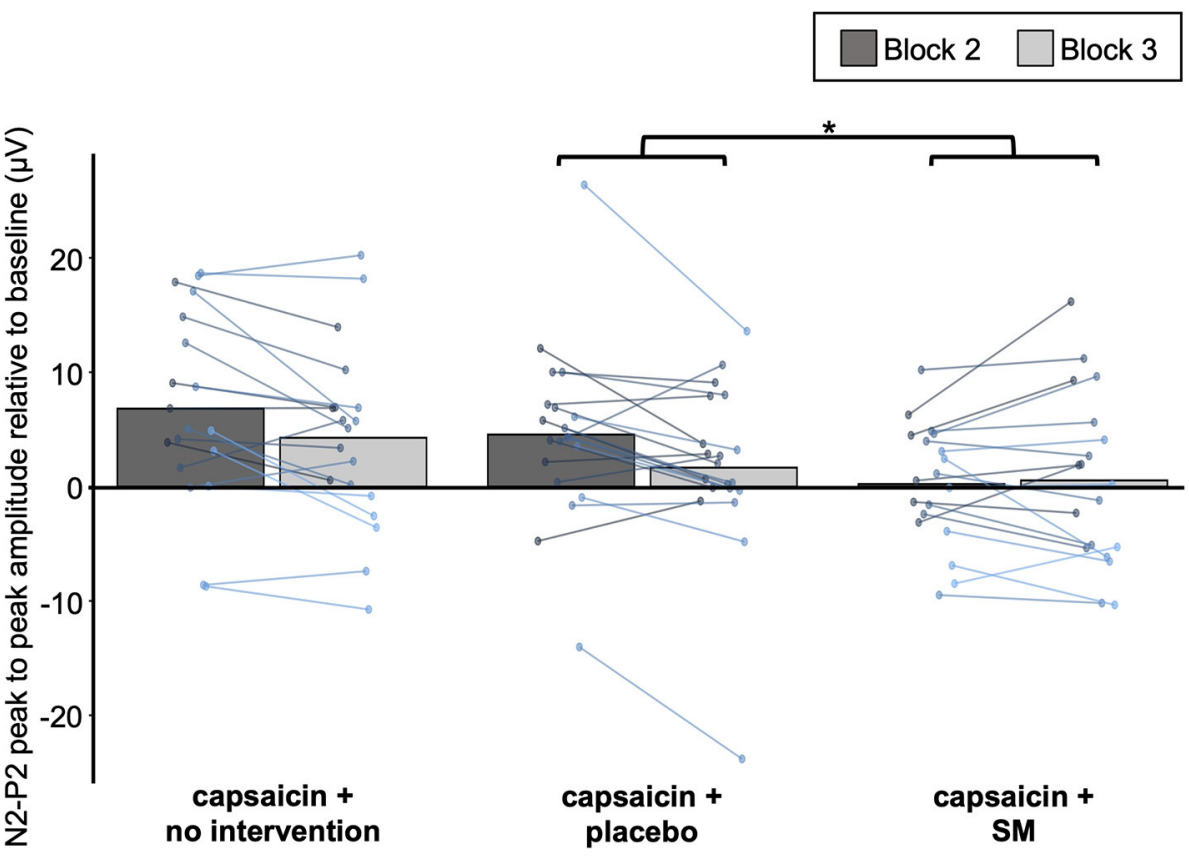

FIGURE 8 | Effect of SM on A $\delta$ fiber LEP. Average A $\delta$ fiber N2-P2 peak to peak amplitude values for the three groups with capsaicin cream before (block 2) and after (block 3 ) the intervention. Data from each participant are represented by linked colored points and the mean of these data points for each block is represented by gray bars. ${ }^{\star} P<0.05$.

tissues. This suggests that SM applied close to, but not directly on the acutely inflamed area may produce more favorable outcomes, but this remains to be investigated with a clinical sample. It should be emphasized that topical capsaicin and acute musculoskeletal injury do not sensitize the same tissues, and SM may produce different effects on capsaicin and clinical pain. In line with this idea, it has been shown in patients with chronic back pain that brain activity related to spontaneous clinical pain differs from the brain activity related to experimental pain evoked in their back (73). However, it should be noted that findings from several studies suggest that SM affects the transmission of spinal nociceptive activity, regardless of the origin of the inputs (cutaneous or myofascial) (23-30), although this remains to be confirmed with neurophysiological measures of spinal cord activity. Therefore, the lack of effect in the present study suggests that SM does not influence spinal nociceptive transmission when it is amplified by peripheral sensitization. Future studies should confirm these findings with other experimental pain models, including muscle pain induced by exercise or intramuscular hypertonic saline.

Secondly, although previous studies have demonstrated that a single SM can decrease experimental pain $(23,74)$, it is possible that a single SM is not sufficient to reduce peripheral sensitization and pain hypersensitivity. This may explain the discrepancy between the present results and a previous study in which capsaicin pain was reduced by multiple SMs during one session (40). Although the clinical relevance of the present results is limited, it is worth noting that in clinical studies, the number of SM is associated with outcomes. For example, a randomized controlled trial on the dose-response effects of SM for chronic low back pain in which participants received either $0,6,12$ or 18 sessions of multiple SMs reported that 12 sessions yielded the most favorable improvements in pain level and disability (75). In addition, another study from the same group investigating the effect of the same doses of SM in participants with chronic cervicogenic headache reported a linear dose-response relationship between the number of SM sessions and the number of days per month with cervicogenic headache, the most effective dose being 18 sessions (76).

Altogether, the findings from the present and previous studies suggest that centrally mediated neurophysiological mechanisms independent of primary hyperalgesia may produce the immediate pain reduction by $\mathrm{SM}$, which may add to anti-inflammatory and other effects later on, in line with the current literature (23-26, 77-80). However, this should be confirmed with clinical populations since the effects of SM may be different on primary hyperalgesia associated with clinical pain. In addition, future studies may lead to different results if the modulation of primary hyperalgesia by SM is examined with mechanical stimuli instead of heat stimuli. It should also be emphasized that SM was applied only once and it remains to be determined whether several SM applied on different segments surrounding the hyperalgesic area may be more effective.

Although previous studies have examined brain activity following SM, no study investigated the effects of brain activity associated with capsaicin, which was used in the present study as an experimental model of tonic pain associated with pain hypersensitivity. The present results show that SM did not 
modulate LEP amplification by capsaicin, in line with the behavioral results. In two previous EEG studies in healthy volunteers, laser pain (81) and secondary hyperalgesia induced by capsaicin (30) were decreased by SM. However, these studies did not examine if primary hyperalgesia was modulated by SM. Reducing primary hyperalgesia may prevent or reduce the development of secondary hyperalgesia, but the present results indicate that the reduction of secondary hyperalgesia induced by capsaicin (30) cannot be explained by this mechanism. In another study in patients with subclinical pain, pain intensity and cerebral oscillations $(1-32 \mathrm{~Hz})$ induced by $80 \mathrm{~s}$ of tonic pain (hand cold-pressor test) were not modulated by SM applied on different regions of the spine (82). In functional magnetic resonance imaging (fMRI) studies, a decrease of pain-related activity was observed following a single SM, in healthy individuals $(83,84)$ and patients with neck pain $(85)$. Other fMRI studies also suggest that SM may reduce chronic low back pain by modulating the saliency network activity or connectivity $(86,87)$. Thus, far, these conflicting findings highlight the need for further research to examine brain activity with protocols in which SM produces clear pain inhibition. Moreover, it should be emphasized that the present study and our previous reports $(30,81)$ were designed to examine brain activity evoked by the selective activation of A- $\delta$ and $C$ fibers, and its modulation by segmental SM, with the hypothesis that segmental inhibition of nociceptive activity in the spinal cord would be reflected in decreased nociceptive activity in the brain. This does not exclude that cerebral processes non-specific to SM may also modulate nociceptive activity. Accordingly, future studies should include all appropriate controls to examine the effects of SM on pain perception and pain-related processes with well-supported hypothesis-driven experimental designs and a mechanistic approach, as proposed previously $(80,88)$.

\section{Expectations and Placebo Effects}

Expectations did not predict any inter-individual differences in the variables of interest. Although some participants expected a large pain relief by the intervention, this did not lead to better outcomes, either in the SM group or the placebo group. Consistent with these results, less than half of participants reported the intervention as effective, regardless of the intervention group. The fact that participants were not aware of different group allocations and interventions may contribute to making expectations and placebo effects more comparable between groups. This may be examined and considered in future studies.

It has been shown that the nocebo effect increases pain ratings and LEPs (89). Capsaicin application may have induced such nocebo effects, competing with and hiding the potential inhibition of A $\delta$ LEP and pain by SM. A measure of expectations relative to capsaicin in addition to a measure of expectations related to the effects of SM and placebo could clarify this issue in a future study.

\section{Significance}

There are several important steps between basic research and clinical practice guidelines, and the objective of this basic study is to provide information on the underlying mechanisms of
SM-induced inhibition of pain amplification due to peripheral sensitization. This is essential to feed applied and clinical research, and eventually, to provide a mechanistic rationale to support clinical practice guidelines. Accordingly, experimental pain models are validated in preclinical research on biomarkers, which may be measured in clinical studies, thereby narrowing the gap between basic and clinical findings (38). Recently, three reviews on the mechanisms of SM $(80,90)$ or manual therapy (91) stated the need for more well-designed mechanistic studies. The present study adds to previous basic studies to guide investigators on which measures should be used in mechanistic clinical trials and which mechanisms may underlie the clinical effects of SM in these clinical trials. Nevertheless, clinical recommendations should be considered cautiously when inferred from experimental pain models that may not completely reflect pathological mechanisms.

\section{CONCLUSION}

In summary, the present results indicate that SM applied segmentally does not reduce the capsaicin-induced amplification of heat pain and the associated nociceptive brain activity. Future studies are needed to examine the modulation of primary heat and mechanical hyperalgesia in patients with chronic spine pain, in whom pathological changes in the dorsal horn of the spinal cord may lead to different results.

\section{DATA AVAILABILITY STATEMENT}

The raw data supporting the conclusions of this article will be made available by the authors, without undue reservation.

\section{ETHICS STATEMENT}

The studies involving human participants were reviewed and approved by Comité d'éthique de la recherche chez l'être humain (UQTR). The patients/participants provided their written informed consent to participate in this study.

\section{AUTHOR CONTRIBUTIONS}

BP contributed to the study design, data collection, analysis and interpretation, and wrote the preliminary version of the manuscript. SN contributed to data collection and analyses. MP contributed to the study design, data collection, analyses, interpretation, wrote the final version of the manuscript, and obtained funding for the study. Each author has contributed significantly to this work and has read and approved the final version of the manuscript.

\section{FUNDING}

This project was funded by the Fondation Chiropratique du Québec, the Natural Science and Engineering Research Council of Canada (\#06659), and the Canadian Foundation for Innovation (\#33731). The contribution of Benjamin Provencher was supported by the Fonds de Recherche du Québec - Santé 
(FRQS) and the Fondation Chiropratique du Québec. The contribution of Stéphane Northon was supported by the Fonds de Recherche du Québec - Nature et Technologie (FRQNT). The contribution of Mathieu Piché was supported by the Fonds de Recherche du Québec - Santé (FRQS).

\section{REFERENCES}

1. Shraim MA, Massé-Alarie H, Hall LM, Hodges PW. Systematic review and synthesis of mechanism-based classification systems for pain experienced in the musculoskeletal system. Clin J Pain. (2020) 36:793-812. doi: 10.1097/AJP.0000000000000860

2. Urits I, Burshtein A, Sharma M, Testa L, Gold PA, Orhurhu V, et al. Low back pain, a comprehensive review: pathophysiology, diagnosis, and treatment. Curr Pain Headache Rep. (2019) 23:23. doi: 10.1007/s11916-019-0757-1

3. Vlaeyen JWS, Maher CG, Wiech K, Van Zundert J, Meloto CB, Diatchenko L, et al. Low back pain. Nat Rev Dis Primers. (2018) 4:52-70. doi: 10.1038/s41572-018-0052-1

4. Hartvigsen J, Hancock MJ, Kongsted A, Louw Q, Ferreira ML, Genevay S, et al. What low back pain is and why we need to pay attention. Lancet. (2018) 391:2356-67. doi: 10.1016/S0140-6736(18)30480-X

5. Raja SN, Meyer RA, Campbell JN. Peripheral mechanisms of somatic pain. Anesthesiology. (1988) 68:571-90. doi: 10.1097/00000542-198804000-00016

6. Treede RD, Meyer RA, Raja SN, Campbell JN. Peripheral and central mechanisms of cutaneous hyperalgesia. Pro Neurobiol. (1992) 38:397421. doi: 10.1016/0301-0082(92)90027-C

7. Baumann TK, Simone DA, Shain CN, LaMotte RH. Neurogenic hyperalgesia: the search for the primary cutaneous afferent fibers that contribute to capsaicin-induced pain and hyperalgesia. J Neurophysiol. (1991) 66:21227. doi: 10.1152/jn.1991.66.1.212

8. Torebjörk HE, LaMotte RH, Robinson CJ. Peripheral neural correlates of magnitude of cutaneous pain and hyperalgesia: simultaneous recordings in humans of sensory judgments of pain and evoked responses in nociceptors with C-fibers. J Neurophysiol. (1984) 51:325-39. doi: 10.1152/jn.1984.51.2.325

9. Matsuda M, Huh Y, Ji RR. Roles of inflammation, neurogenic inflammation, and neuroinflammation in pain. J Anesth. (2019) 33:131-9. doi: 10.1007/s00540-018-2579-4

10. Hsieh M-T, Donaldson LF, Lumb BM. Differential contributions of Aand C-nociceptors to primary and secondary inflammatory hypersensitivity in the rat. Pain. (2015) 156:1074-83. doi: 10.1097/j.pain.00000000000 00151

11. LaMotte RH, Lundberg LE, Torebjörk HE. Pain, hyperalgesia and activity in nociceptive $\mathrm{C}$ units in humans after intradermal injection of capsaicin. $J$ Physiol. (1992) 448:749-64. doi: 10.1113/jphysiol.1992.sp019068

12. You HJ, Lei J, Sui MY, Huang L, Tan YX, Tjølsen A, et al. Endogenous descending modulation: spatiotemporal effect of dynamic imbalance between descending facilitation and inhibition of nociception. J Physiol. (2010) 588(Pt 21):4177-88. doi: 10.1113/jphysiol.2010.196923

13. Magerl W, Fuchs PN, Meyer RA, Treede RD. Roles of capsaicininsensitive nociceptors in cutaneous pain and secondary hyperalgesia. Brain J Neurol. (2001) 124:1754-64. doi: 10.1093/brain/124. 9.1754

14. Nijs J, George SZ, Clauw DJ, Fernández-de-las-Peñas C, Kosek E, Ickmans $\mathrm{K}$, et al. Central sensitisation in chronic pain conditions: latest discoveries and their potential for precision medicine. Lancet Rheumatol. (2021) 3:e383e92. doi: 10.1016/S2665-9913(21)00032-1

15. den Bandt HL, Paulis WD, Beckwée D, Ickmans K, Nijs J, Voogt L. Pain mechanisms in low back pain: a systematic review with metaanalysis of mechanical quantitative sensory testing outcomes in people with nonspecific low back pain. J Orthop Sports Phys Therapy. (2019) 49:698715. doi: 10.2519/jospt.2019.8876

16. Beliveau PJH, Wong JJ, Sutton DA, Simon NB, Bussieres AE, Mior SA, et al. The chiropractic profession: a scoping review of utilization rates, reasons for seeking care, patient profiles, and care provided. Chiropr Man Therap. (2017) 25:35-52. doi: 10.1186/s12998-017-0165-8

\section{SUPPLEMENTARY MATERIAL}

The Supplementary Material for this article can be found online at: https://www.frontiersin.org/articles/10.3389/fpain. 2021.733727/full\#supplementary-material

17. Millan M, Leboeuf-Yde C, Budgell B, Amorim MA. The effect of spinal manipulative therapy on experimentally induced pain: a systematic literature review. Chiropr Manual Therap. (2012) 20:26. doi: 10.1186/2045-709X-20-26

18. Coronado RA, Gay CW, Bialosky JE, Carnaby GD, Bishop MD, George SZ. Changes in pain sensitivity following spinal manipulation: a systematic review and meta-analysis. J Electromyog Kinesiol. (2012) 22:752-67. doi: 10.1016/j.jelekin.2011.12.013

19. Kolber MR, Ton J, Thomas B, Kirkwood J, Moe S, Dugré N, et al. PEER systematic review of randomized controlled trials: management of chronic low back pain in primary care. Can Family Phys. (2021) 67:e20-30. doi: $10.46747 / \mathrm{cfp} .6701 \mathrm{e} 20$

20. Stochkendahl MJ, Kjaer P, Hartvigsen J, Kongsted A, Aaboe J, Andersen M, et al. National clinical guidelines for non-surgical treatment of patients with recent onset low back pain or lumbar radiculopathy. Eur Spine J. (2018) 27:60-75. doi: 10.1007/s00586-017-5099-2

21. Bussières AE, Stewart G, Al-Zoubi F, Decina P, Descarreaux M, Haskett D, et al. Spinal manipulative therapy and other conservative treatments for low back pain: a guideline from the canadian chiropractic guideline initiative. $J$ Manipul Physiol Therap. (2018) 41:265-93. doi: 10.1016/j.jmpt.2017.12.004

22. Foster NE, Anema JR, Cherkin D, Chou R, Cohen SP, Gross DP, et al. Prevention and treatment of low back pain: evidence, challenges, and promising directions. Lancet. (2018) 391:236883. doi: 10.1016/S0140-6736(18)30489-6

23. Randoll C, Gagnon-Normandin V, Tessier J, Bois S, Rustamov N, O'Shaughnessy J, et al. The mechanism of back pain relief by spinal manipulation relies on decreased temporal summation of pain. Neuroscience. (2017) 349:220-8. doi: 10.1016/j.neuroscience.2017.03.006

24. George SZ, Bishop MD, Bialosky JE, Zeppieri G, Jr., Robinson ME. Immediate effects of spinal manipulation on thermal pain sensitivity: an experimental study. BMC Muscul Dis. (2006) 7:68-78. doi: 10.1186/1471-2474-7-68

25. Bialosky JE, Bishop MD, Robinson ME, Zeppieri G, Jr., George SZ. Spinal manipulative therapy has an immediate effect on thermal pain sensitivity in people with low back pain: a randomized controlled trial. Phys Ther. (2009) 89:1292-303. doi: 10.2522/ptj.20090058

26. Bialosky JE, George SZ, Horn ME, Price DD, Staud R, Robinson ME. Spinal manipulative therapy-specific changes in pain sensitivity in individuals with low back pain (NCT01168999). J Pain. (2014) 15:13648. doi: 10.1016/j.jpain.2013.10.005

27. Bialosky JE, Bishop MD, Robinson ME, Barabas JA, George SZ. The influence of expectation on spinal manipulation induced hypoalgesia: an experimental study in normal subjects. BMC Muscul Dis. (2008) 9:19. doi: 10.1186/1471-2474-9-19

28. Bishop MD, Beneciuk JM, George SZ. Immediate reduction in temporal sensory summation after thoracic spinal manipulation. Spine J. (2011) 11:4406. doi: 10.1016/j.spinee.2011.03.001

29. Penza CW, Horn ME, George SZ, Bishop MD. Comparison of 2 lumbar manual therapies on temporal summation of pain in healthy volunteers. $J$ Pain. (2017) 18:1397-408. doi: 10.1016/j.jpain.2017.07.007

30. Gevers-Montoro C, Provencher B, Northon S, Stedile-Lovatel JP, Ortega de Mues A, Piché M. Chiropractic spinal manipulation prevents secondary hyperalgesia induced by topical capsaicin in healthy individuals. Front Pain Res. (2021) 2. doi: 10.3389/fpain.2021.702429

31. Arribas-Romano A, Fernández-Carnero J, Molina-Rueda F, Angulo-DiazParreño S, Navarro-Santana MJ. Efficacy of physical therapy on nociceptive pain processing alterations in patients with chronic musculoskeletal pain: a systematic review and meta-analysis. Pain Med. (2020) 21:250217. doi: $10.1093 / \mathrm{pm} / \mathrm{pnz} 366$

32. Wong AY, Parent EC, Dhillon SS, Prasad N, Kawchuk GN. Do participants with low back pain who respond to spinal manipulative therapy differ 
biomechanically from nonresponders, untreated controls or asymptomatic controls? Spine. (2015) 40:1329-37. doi: 10.1097/BRS.00000000000000981

33. Fritz JM, Koppenhaver SL, Kawchuk GN, Teyhen DS, Hebert JJ, Childs JD. Preliminary investigation of the mechanisms underlying the effects of manipulation: exploration of a multivariate model including spinal stiffness, multifidus recruitment, and clinical findings. Spine. (2011) 36:177281. doi: 10.1097/BRS.0b013e318216337d

34. Nim CG, Kawchuk GN, Schiøttz-Christensen B, O'Neill S. The effect on clinical outcomes when targeting spinal manipulation at stiffness or pain sensitivity: a randomized trial. Sci Rep. (2020) 10:14615. doi: 10.1038/s41598-020-71557-y

35. Nim CG, O'Neill S, Geltoft AG, Jensen LK, Schiøttz-Christensen B, Kawchuk GN. A cross-sectional analysis of persistent low back pain, using correlations between lumbar stiffness, pressure pain threshold, and heat pain threshold. Chiropr Man Therap. (2021) 29:34. doi: 10.1186/s12998-021-00391-4

36. Price RC, Gandhi W, Nadeau C, Tarnavskiy R, Qu A, Fahey E, et al. Characterization of a novel capsaicin/heat ongoing pain model. Eur J Pain. (2018) 22:370-84. doi: 10.1002/ejp.1126

37. Fattori V, Hohmann MS, Rossaneis AC, Pinho-Ribeiro FA, Verri WA. Capsaicin: current understanding of its mechanisms and therapy of pain and other pre-clinical and clinical uses. Molecules. (2016) 21:84477. doi: $10.3390 /$ molecules21070844

38. Quesada C, Kostenko A, Ho I, Leone C, Nochi Z, Stouffs A, et al. Human surrogate models of central sensitization: a critical review and practical guide. Eur J Pain. (2021) 25:1389-428. doi: 10.1002/ejp.1768

39. Ilie MA, Caruntu C, Tampa M, Georgescu SR, Matei C, Negrei C, et al. Capsaicin: physicochemical properties, cutaneous reactions and potential applications in painful and inflammatory conditions. Exp Ther Med. (2019) 18:916-25. doi: 10.3892/etm.2019.7513

40. Mohammadian P, Gonsalves A, Tsai C, Hummel T, Carpenter T. Areas of capsaicin-induced secondary hyperalgesia and allodynia are reduced by a single chiropractic adjustment: a preliminary study. J Manipul Physiol Ther. (2004) 27:381-7. doi: 10.1016/j.jmpt.2004.05.002

41. Bromm B, Jahnke MT, Treede RD. Responses of human cutaneous afferents to CO2 laser stimuli causing pain. Exp Brain Res. (1984) 55:15866. doi: 10.1007/BF00240510

42. Plaghki L, Mouraux A. How do we selectively activate skin nociceptors with a high power infrared laser? Physiol Biophys Laser Stimul.. (2003) 33:26977. doi: $10.1016 /$ j. neucli.2003.10.003

43. Madden VJ, Catley MJ, Grabherr L, Mazzola F, Shohag M, Moseley GL. The effect of repeated laser stimuli to ink-marked skin on skin temperaturerecommendations for a safe experimental protocol in humans. Peer J. (2016) 4:e1577. doi: 10.7717/peerj.1577

44. Schaffler K, Nicolas LB, Borta A, Brand T, Reitmeir P, Roebling R, et al. Investigation of the predictive validity of laser-EPs in normal, UVB-inflamed and capsaicin-irritated skin with four analgesic compounds in healthy volunteers. Brit J Clin Pharmacol. (2017) 83:1424-35. doi: 10.1111/bcp. 13247

45. Lin RL, Douaud G, Filippini N, Okell TW, Stagg CJ, Tracey I. Structural connectivity variances underlie functional and behavioral changes during pain relief induced by neuromodulation. Sci Rep. (2017) 7:41603. doi: 10.1038/srep41603

46. Segerdahl AR, Mezue M, Okell TW, Farrar JT, Tracey I. The dorsal posterior insula subserves a fundamental role in human pain. Nat Neurosci. (2015) 18:499-500. doi: 10.1038/nn.3969

47. Page I, Biner E, Descarreaux M. Vertebral displacements and muscle activity during manual therapy: distinct behaviors between spinal manipulation and mobilization. J Manipulative Physiol Ther. (2018) 41:753-61. doi: 10.1016/j.jmpt.2018.07.004

48. Herzog W. The biomechanics of spinal manipulation. J Bodywork Mov Ther. (2010) 14:280-6. doi: 10.1016/j.jbmt.2010.03.004

49. Triano JJ, Giuliano D, Kanga I, Starmer D, Brazeau J, Screaton CE, et al. Consistency and malleability of manipulation performance in experienced clinicians: a pre-post experimental design. J Manipulative Physiol Ther. (2015) 38:407-15. doi: 10.1016/j.jmpt.2015.05.002

50. Pickar JG, Bolton PS. Spinal manipulative therapy and somatosensory activation. J Electromyog Kinesiol. (2012) 22:78594. doi: 10.1016/j.jelekin.2012.01.015
51. Downie AS, Vemulpad S, Bull PW. Quantifying the high-velocity, lowamplitude spinal manipulative thrust: a systematic review. J Manipulative Physiol Ther. (2010) 33:542-53. doi: 10.1016/j.jmpt.2010.08.001

52. Picchiottino M, Honore M, Leboeuf-Yde C, Gagey O, Cottin F, Hallman DM. The effect of a single spinal manipulation on cardiovascular autonomic activity and the relationship to pressure pain threshold: a randomized, cross-over, sham-controlled trial. Chiropr Man Therap. (2020) 28:7. doi: 10.1186/s12998-019-0293-4

53. Chaibi A, Šaltyte Benth J, Bjørn Russell M. Validation of placebo in a manual therapy randomized controlled trial. Sci Rep. (2015) 5:11774. doi: 10.1038/srep11774

54. Goffaux P, Redmond WJ, Rainville P, Marchand S. Descending analgesiawhen the spine echoes what the brain expects. Pain. (2007) 130:13743. doi: 10.1016/j.pain.2006.11.011

55. Delorme A, Makeig S. EEGLAB: an open source toolbox for analysis of singletrial EEG dynamics including independent component analysis. J Neurosci Meth. (2004) 134:9-21. doi: 10.1016/j.jneumeth.2003.10.009

56. Lenoir C, Plaghki L, Mouraux A, van den Broeke EN. Quickly responding Cfibre nociceptors contribute to heat hypersensitivity in the area of secondary hyperalgesia. J Physiol. (2018) 596:4443-55. doi: 10.1113/JP275977

57. Torta DM, Churyukanov MV, Plaghki L, Mouraux A. The effect of heterotopic noxious conditioning stimulation on $\mathrm{A} \delta$-, $\mathrm{C}$ - and $\mathrm{A} \beta$-fibre brain responses in humans. Eur J Neurosci. (2015) 42:2707-15. doi: 10.1111/ejn.13071

58. van den Broeke EN, Mouraux A. Enhanced brain responses to Cfiber input in the area of secondary hyperalgesia induced by highfrequency electrical stimulation of the skin. J Neurophysiol. (2014) 112:205966. doi: 10.1152/jn.00342.2014

59. Bragard D, Chen AC, Plaghki L. Direct isolation of ultra-late (C-fibre) evoked brain potentials by $\mathrm{CO} 2$ laser stimulation of tiny cutaneous surface areas in man. Neurosci Lett. (1996) 209:81-4. doi: 10.1016/0304-3940(96)12604-5

60. Hu L, Cai MM, Xiao P, Luo F, Iannetti GD. Human brain responses to concomitant stimulation of Adelta and C nociceptors. J Neurosci. (2014) 34:11439-51. doi: 10.1523/JNEUROSCI.1355-14.2014

61. Jankovski A, Plaghki L, Mouraux A. Reliable EEG responses to the selective activation of C-fibre afferents using a temperature-controlled infrared laser stimulator in conjunction with an adaptive staircase algorithm. Pain. (2013) 154:1578-87. doi: 10.1016/j.pain.2013.04.032

62. Perchet C, Godinho F, Mazza S, Frot M, Legrain V, Magnin M, et al. Evoked potentials to nociceptive stimuli delivered by $\mathrm{CO} 2$ or Nd:YAP lasers. Clin Neurophysiol. (2008) 119:2615-22. doi: 10.1016/j.clinph.2008.06.021

63. Cousineau D. Confidence intervals in within-subject designs: a simpler solution to Loftus and Masson's method. Tutor Quantit Meth Psychol. (2005) 1:42-5. doi: 10.20982/tqmp.01.1.p042

64. O'Neill J, Brock C, Olesen AE, Andresen T, Nilsson M, Dickenson AH. Unravelling the mystery of capsaicin: a tool to understand and treat pain. Pharmacol Rev. (2012) 64:939-71. doi: 10.1124/pr.112.006163

65. Schaffler K, Reitmeir P, Gschanes A, Eggenreich U. Comparison of the analgesic effects of a fixed-dose combination of orphenadrine and diclofenac (Neodolpasse) with its single active ingredients diclofenac and orphenadrine: a placebo-controlled study using laser-induced somatosensoryevoked potentials from capsaicin-induced hyperalgesic human skin. Drugs RD. (2005) 6:189-99. doi: 10.2165/00126839-200506040-00001

66. Hüllemann P, Watfeh R, Shao YQ, Nerdal A, Binder A, Baron R. Peripheral sensitization reduces laser-evoked potential habituation. Neurophysiol Clin Clin Neurophysiol. (2015) 45:457-67. doi: 10.1016/j.neucli.2015.10.088

67. Tzabazis AZ, Klukinov M, Crottaz-Herbette S, Nemenov MI, Angst MS, Yeomans DC. Selective nociceptor activation in volunteers by infrared diode laser. Mol Pain. (2011) 7:18-. doi: 10.1186/1744-8069-7-18

68. Domnick C, Hauck M, Casey KL, Engel AK, Lorenz J. C-fiber-related EEGoscillations induced by laser radiant heat stimulation of capsaicin-treated skin. J Pain Res. (2009) 2:49-56. doi: 10.2147/JPR.S4860

69. O’Neill S, Larsen JB, Nim C, Arendt-Nielsen L. Topographic mapping of pain sensitivity of the lower back - a comparison of healthy controls and patients with chronic non-specific low back pain. Scand J Pain. (2019) 19:2537. doi: 10.1515/sjpain-2018-0113

70. O'Neill S, Manniche C, Graven-Nielsen T, Arendt-Nielsen L. Generalized deep-tissue hyperalgesia in patients with chronic low-back pain. Eur J Pain. (2007) 11:415-20. doi: 10.1016/j.ejpain.2006.05.009 
71. Ross GB, Mavor M, Brown SHM, Graham RB. The effects of experimentally induced low back pain on spine rotational stiffness and local dynamic stability. Annal Biomed Eng. (2015) 43:2120-30. doi: 10.1007/s10439-015-1268-9

72. Pinto BL, Beaudette SM, Graham RB, Brown SHM. Experimentally induced neck pain causes a decrease in thoracic but not lumbar spine stability. J Biomech. (2019) 90:78-83. doi: 10.1016/j.jbiomech.2019.04.031

73. Baliki MN, Chialvo DR, Geha PY, Levy RM, Harden RN, Parrish TB, et al. Chronic pain and the emotional brain: specific brain activity associated with spontaneous fluctuations of intensity of chronic back pain. J Neurosci. (2006) 26:12165-73. doi: 10.1523/JNEUROSCI.3576-06.2006

74. Aspinall SL, Jacques A, Leboeuf-Yde C, Etherington SJ, Walker BF. No difference in pressure pain threshold and temporal summation after lumbar spinal manipulation compared to sham: a randomised controlled trial in adults with low back pain. Muscul Sci Pract. (2019) 43:1825. doi: 10.1016/j.msksp.2019.05.011

75. Haas M, Vavrek D, Peterson D, Polissar N, Neradilek MB. Doseresponse and efficacy of spinal manipulation for care of chronic low back pain: a randomized controlled trial. Spine J. (2014) 14:110616. doi: 10.1016/j.spinee.2013.07.468

76. Haas M, Bronfort G, Evans R, Schulz C, Vavrek D, Takaki L, et al. Dose-response and efficacy of spinal manipulation for care of cervicogenic headache: a dual-center randomized controlled trial. Spine J. (2018) 18:174154. doi: 10.1016/j.spinee.2018.02.019

77. Teodorczyk-Injeyan JA, McGregor M, Triano JJ, Injeyan SH. Elevated production of nociceptive CC chemokines and sE-selectin in patients with low back pain and the effects of spinal manipulation: a nonrandomized clinical trial. Clin J Pain. (2018) 34:68-75. doi: 10.1097/AJP.0000000000000507

78. Teodorczyk-Injeyan JA, Injeyan HS, Ruegg R. Spinal manipulative therapy reduces inflammatory cytokines but not substance $\mathrm{P}$ production in normal subjects. J Manipulative Physiol Ther. (2006) 29:14-21. doi: 10.1016/j.jmpt.2005.10.002

79. Roy RA, Boucher JP, Comtois AS. Inflammatory response following a shortterm course of chiropractic treatment in subjects with and without chronic low back pain. J Chiropr Med. (2010) 9:107-14. doi: 10.1016/j.jcm.2010.06.002

80. Gevers-Montoro C, Provencher B, Descarreaux M, Ortega de Mues A, Piché M. Neurophysiological mechanisms of chiropractic spinal manipulation for spine pain. Eur J Pain. (2021) 25:1429-48. doi: 10.1002/ejp.1773

81. Provencher B, Northon S, Gevers Montoro C, O'Shaughnessy J, Piché M. Effects of chiropractic spinal manipulation on laser-evoked pain and brain activity. J Physiol Sci. (2021) 71:20. doi: 10.1186/s12576-021-00804-2

82. Navid MS, Lelic D, Niazi IK, Holt K, Mark EB, Drewes AM, et al. The effects of chiropractic spinal manipulation on central processing of tonic pain - a pilot study using standardized low-resolution brain electromagnetic tomography (sLORETA). Sci Rep. (2019) 9:6925. doi: 10.1038/s41598-019-42984-3

83. Sparks C, Cleland JA, Elliott JM, Zagardo M, Liu WC. Using functional magnetic resonance imaging to determine if cerebral hemodynamic responses to pain change following thoracic spine thrust manipulation in healthy individuals. J Orthop Spor Phys Ther. (2013) 43:340-8. doi: 10.2519/jospt.2013.4631

84. Gay CW, Robinson ME, George SZ, Perlstein WM, Bishop MD. Immediate changes after manual therapy in resting-state functional connectivity as measured by functional magnetic resonance imaging in participants with induced low back pain. J Manipul Physiol Ther. (2014) 37:61427. doi: 10.1016/j.jmpt.2014.09.001

85. Sparks CL, Liu WC, Cleland JA, Kelly JP, Dyer SJ, Szetela KM, et al. Functional magnetic resonance imaging of cerebral hemodynamic responses to pain following thoracic thrust manipulation in individuals with neck pain: a randomized trial. J Manipulative Physiol Ther. (2017) 40:62534. doi: 10.1016/j.jmpt.2017.07.010

86. Isenburg K, Mawla I, Loggia ML, Ellingsen DM, Protsenko E, Kowalski MH et al. Increased salience network connectivity following manual therapy is associated with reduced pain in chronic low back pain patients. J Pain. (2021) 22:545-55. doi: 10.1016/j.jpain.2020.11.007

87. Ellingsen DM, Napadow V, Protsenko E, Mawla I, Kowalski MH, Swensen $\mathrm{D}$, et al. Brain mechanisms of anticipated painful movements and their modulation by manual therapy in chronic low back pain. J Pain. (2018) 19:1352-65. doi: 10.1016/j.jpain.2018.05.012

88. Meyer A-L, Amorim M-A, Schubert M, Schweinhardt P, Leboeuf-Yde C. Unravelling functional neurology: does spinal manipulation have an effect on the brain? - a systematic literature review. Chiropr Manual Ther. (2019) 27:60. doi: 10.1186/s12998-019-0265-8

89. Pazzaglia C, Testani E, Giordano R, Padua L, Valeriani M. Expectation to feel more pain disrupts the habituation of laser-pain rating and laser-evoked potential amplitudes. Neuroscience. (2016) 333:244-51. doi: 10.1016/j.neuroscience.2016.07.027

90. Gyer G, Michael J, Inklebarger J, Tedla JS. Spinal manipulation therapy: is it all about the brain? A current review of the neurophysiological effects of manipulation. J Integr Med. (2019) 17:328-37. doi: 10.1016/j.joim.2019. 05.004

91. Bialosky JE, Beneciuk JM, Bishop MD, Coronado RA, Penza CW, Simon $\mathrm{CB}$, et al. Unraveling the mechanisms of manual therapy: modeling an approach. J Orthop Sports Phys Ther. (2018) 48:8-18. doi: 10.2519/jospt.20 18.7476

Conflict of Interest: The authors declare that the research was conducted in the absence of any commercial or financial relationships that could be construed as a potential conflict of interest.

Publisher's Note: All claims expressed in this article are solely those of the authors and do not necessarily represent those of their affiliated organizations, or those of the publisher, the editors and the reviewers. Any product that may be evaluated in this article, or claim that may be made by its manufacturer, is not guaranteed or endorsed by the publisher.

Copyright (C) 2021 Provencher, Northon and Piché. This is an open-access article distributed under the terms of the Creative Commons Attribution License (CC BY). The use, distribution or reproduction in other forums is permitted, provided the original author(s) and the copyright owner(s) are credited and that the original publication in this journal is cited, in accordance with accepted academic practice. No use, distribution or reproduction is permitted which does not comply with these terms. 